\title{
On the Relevance of the Polar $\beta$-Phase of
}

\section{Poly(vinylidene fluoride) for High Performance}

\section{Lithium-Ion Battery Separators}

Manab Kundu ${ }^{\dagger, \#}$, Carlos M. Costa ${ }^{\ddagger, \|, \#, *}$, Juliana Dias ${ }^{\ddagger, \|}$, Alberto Maceiras ${ }^{ \pm}$, José Luis

Vilas $^{ \pm, \neq}$, Senentxu Lanceros-Méndez ${ }^{ \pm, ", *}$

$†$ Department of Materials Science and Engineering, Norwegian University of Science and Technology, N-7491 Trondheim, Norway

†Centro de Física, Universidade do Minho, 4710-057 Braga, Portugal

„Centro de Química, Universidade do Minho, 4710-057 Braga, Portugal

×BCMaterials, Parque Científico y Tecnológico de Bizkaia, 48160 Derio, Spain

¥Departamento de Química Física, Facultad de Ciencia y Tecnología, Universidad del

País Vasco/EHU, Apdo. 644, Bilbao E-48080, Spain

"IKERBASQUE, Basque Foundation for Science, 48013 Bilbao, Spain

\#equal contribution

* Corresponding Authors

Email: cmscosta@fisica.uminho.pt (C. M. Costa), senentxu.lanceros@bcmaterials.net

(S. Lanceros-Mendez). 
ABSTRACT: Separator membranes based on poly(vinylidene fluoride), PVDF, poly(vinylidene fluoride-co-trifluoroethylene), PVDF-TrFE, poly(vinylidene fluorideco-hexafluropropylene), PVDF-HFP and poly(vinylidene fluoride-cochlorotrifluoroethylene), PVDF-CTFE were prepared by solvent casting method using $\mathrm{N}, \mathrm{N}$-dimethylformamide (DMF) as solvent. In all cases, the same polymer/solvent ratio and solvent evaporation temperature were used. For all membranes, porous microstructure is achieved with a degree of porosity larger than $50 \%$. The $\beta$-phase content as well as degree of crystallinity were different for each membrane, which were lower for the co-polymer membranes when compared with PVDF. On the other hand, the observed ionic conductivity values, electrolyte uptake, tortuosity and MacMullin number were similar for all membranes. The electrochemical performance of the separator membranes was evaluated in $\mathrm{Li} / \mathrm{C}-\mathrm{LiFePO}_{4}$ half-cell configuration showing good cyclability and rate capability for all membranes. Among the all separator membranes, PVDF-TrFE demonstrate the best electrochemical performance, with a discharge capacity value of 87 mAh. $\mathrm{g}^{-1}$ after 50 cycles with a capacity retention of $78 \%$ at $2 \mathrm{C}$.

Finally, the correlation between the $\beta$-phase content in the membranes and the cycling performance was demonstrated (which was significant at high-C rates): larger $\beta$-phase contents, leading higher polarity, facilitates faster lithium ion migration within the separator for similar microstructures. 


\section{INTRODUCTION}

Advanced energy storage systems are one of the main issues related with energetic challenges, being essential to increase their efficiency and autonomy in order to improve their applicability in portable electronic products (mobile-phone, computers, e-labels, epackaging, disposable medical testers, drug delivery patches, etc) and electric vehicles $(\mathrm{EV})$, hybrid electric vehicles (HEV) ${ }^{1-3}$.

These systems are adequate for reducing $\mathrm{CO}_{2}$ emission and dependence from fossil resources once the stored energy is generated by environmental friendly energy sources, such as photovoltaic, wind and geothermal ${ }^{4,5}$.

The most widely used energy storage system are based on electrochemical cells and more specifically rechargeable batteries ${ }^{6}$. There are different types of rechargeable batteries such as lead acid, nickel cadmium and sodium nickel chloride batteries, but the one with the largest market share are lithium-ion batteries. This fact is due to their interesting characteristics, such as being lighter and cheaper, showing high energy density (between 100 and $150 \mathrm{Wh}_{\mathrm{kg}}{ }^{-1}$ ) and improved charge/discharge cycles ${ }^{6-8}$.

The main components of lithium-ion batteries are the two electrodes with different electrochemical potential (anode and cathode) and the separator, the later preventing the short-circuit of the battery through the separation of both electrodes and controlling the number and mobility of the lithium ions during the charge and discharge processes ${ }^{9,10}$. The separator membrane is typically composed by a porous polymer membrane soaked with an electrolyte solution (i.e, a lithium salt in a mixture of one or more organic solvents) ${ }^{11}$. There are other types of separators such as composites and polymer blends but the most used ones are single polymers. The main characteristics to be tailored in the separator membranes are permeability, porosity/pore size, electrolyte absorption and retention, chemical, mechanical and thermal stability ${ }^{9}$. 
The control of all those parameters is relevant, but one of the key parameter of the separators is the morphology (porosity and pore size), as it not only affects battery performance but also the stability of the assembly through their mechanical properties ${ }^{12}$. The most used polymers for separator membranes are poly(ethylene) (PE) ${ }^{13}$, poly(propylene) (PP) ${ }^{14}$, poly(ethylene oxide (PEO) ${ }^{15}$, poly(acrylonitrile) (PAN) ${ }^{16}$, poly(vinylidene fluoride) 17,18 and its copolymers (poly(vinylidene fluoride-cotrifluoroethylene), PVDF-TrFE ${ }^{19}$, poly(vinylidene fluoride-co-hexafluoropropylene), PVDF-HFP ${ }^{20}$, and poly(vinylidene fluoride-co-chlorotrifluoroethylene), PVDF-CTFE) 21.

PVDF and its co-polymers show excellent advantages for their use as separator membranes in single 9,22 and/or composite ${ }^{10,23}$ form in comparison to polyolefins due to their high dipolar moment (i.e, $5 \times 10^{-30}$ C.m for $\alpha$-phase PVDF and $8 \times 10^{-30}$ C.m for $\beta$ phase PVDF ${ }^{24}$ ) and large dielectric constant for a polymer material, which can assist ionization of the lithium salts ${ }^{24}$. Further, PVDF composites based on glass fiber mats ${ }^{25}$, green polymers such as cellulose ${ }^{26}$ and single ion conductors ${ }^{27}$ represent new directions in the development of novel lithium ion battery separators.

These polymers also show excellent thermal and mechanical properties, wettability in organic solvent, are chemically inert and stable in cathodic environment. Moreover their porosity can be easily tailored based on the requirement ${ }^{28}$. There are different experimental procedures in order to obtain the electroactive $\beta$-phase of PVDF and their co-polymer, the phase with the largest polarity and dielectric constant of all polymorphs of PVDF ${ }^{24}$. Thus, for the single polymer in a binary polymer/solvent solution, it is possible to tailor microstructure and phase content by proper selection of the polymer/solvent ratio and solvent evaporation temperature ${ }^{29}$. Typically, the porous microstructure of PVDF and its co-polymers is obtained through the solvent evaporation 
at temperatures below $30^{\circ} \mathrm{C}{ }^{24,29}$. For PVDF-CTFE, the $\beta$-phase increases with increasing the solvent evaporation temperature from a solution with polymer/solvent ratio of 20 wt. $\%{ }^{30}$.

The microstructure and physical properties of PVDF co-polymers is typically tailored through non-solvent induced phase separation (NIPS), the final microstructure of the membrane depending on volume fraction of the copolymer solution, film thickness, time exposure to air, non-solvent, and temperature of the coagulation bath ${ }^{31,32}$.

In particular, homogeneous porous membranes have been obtained from PVDF-CTFE with degrees of crystallinity between $15 \%$ and $23 \%$ and $\beta$-phase contents ranging from 33 to $100 \%$, depending on the temperature of the water-based coagulation bath ${ }^{31}$.

In order to obtain porous separator membranes based on PVDF and its copolymers, different processing techniques such as dry and wet chemical processes ${ }^{33}$, electrospinning ${ }^{34}$, pre-irradiation grafting ${ }^{35}$ and solvent casting technique with thermally induced phase separation (TIPS) ${ }^{36}$ can be applied.

It has been previously demonstrated that the cycling performance of PVDF based separator membranes depend on the membrane structure, i.e, degree of porosity and pore size: the degree of porosity of the separator membrane determines the electrolyte solution uptake which in turn affects the ionic conductivity value of the separator ${ }^{37}$. On the other hand, the effect of the polymer phase, being more or less polar, has not been properly addressed.

Thus, the goal of the present work is to prepare membranes from PVDF and co-polymers with different $\beta$-phase content, while maintaining the similar microstructure of the membrane, in order to understand its effect into the cycling performance of the battery. 


\section{EXPERIMENTAL SECTIONS}

\subsection{MATERIALS}

\subsubsection{SEPARATOR MEMBRANES}

Poly(vinylidene fluoride), PVDF (Solef 6020, $\mathrm{M}_{\mathrm{w}}=700 \mathrm{~kg} \cdot \mathrm{mol}^{-1}$ ), poly $($ vinylidene fluoride-co-trifluoroethylene), PVDF-TrFE (Solvene 250, $\mathrm{M}_{\mathrm{w}}=150-400 \mathrm{~kg} \cdot \mathrm{mol}^{-1} ; 70$ wt\% of VDF content), poly(vinylidene fluoride-co-hexafluropropylene), PVDF-HFP (Solef $21216, \mathrm{Mw}=600 \mathrm{~kg} \cdot \mathrm{mol}^{-1} ; 12 \mathrm{wt} \%$ of HFP content) and poly(vinylidene fluorideco-chlorotrifluoroethylene) PVDF-CTFE (Solef 31 508; Mw =270-290 kg mol-1; 18.66 wt\% CTFE content) were supplied by Solvay. The solvent N,N-dimethylformamide DMF $(99.5 \%)$ was purchased from Merck.

\subsubsection{CATHODE ELECTRODE}

Poly(vinylidene fluoride) (PVDF, Solef 5130, Mw=1000-1300 kg.mol ${ }^{-1}$ ), C-LiFePO 4 (LFP, Particle size: D10 $=0.2 \mu \mathrm{m}, \mathrm{D} 50=0.5 \mu \mathrm{m}$ and D90 $=1.9 \mu \mathrm{m})$, and carbon black (Super P-C45) were acquired from Solvay, Phostech Lithium and Timcal Graphite \& Carbon, respectively.

The solvent N-methyl-1-pyrrolidone (NMP) and conventional electrolyte, $1 \mathrm{M} \mathrm{LiPF} 6$ in ethylene carbonate-diethyl carbonate (EC-DEC, 1:1 vol) were purchased from Fluka and Solvionic, respectively.

\subsection{PROCESSING OF THE MEMBRANES}

Each polymer was dissolved in DMF under magnetic stirring in a polymer/solvent ration of $15 / 85 \mathrm{wt} \%$ at room temperature during 3 hours. After complete dissolution of the polymer, a transparent and homogeneous solution was obtained. Then, the polymer solution was spread on a clean glass substrate by doctor blade and the solvent evaporation 
was achieved at $25^{\circ} \mathrm{C}$ for 15 days within an air oven (Binder, ED23), in order to obtain the porous microstructure ${ }^{37}$.

The separator membranes prepared were identified by the name of polymer, i.e, PVDF, PVDF-TrFE, PVDF-HFP and PVDF-CTFE. The different co-polymers were selected to obtain a suitable variation of the $\beta$ phase content in the membranes.

\subsection{MEMBRANE CHARACTERIZATION}

The morphology of the different membranes was evaluated by scanning electron microscopy (SEM) (FEI Nova 200 (FEG/SEM)) with an accelerating voltage of $10 \mathrm{kV}$. Infrared measurements were carried out with a Jasco FT/IR-4100 system in the attenuated total reflection (ATR) mode between 650 and $4000 \mathrm{~cm}^{-1} .32$ scans were performed for each sample with a resolution of $4 \mathrm{~cm}^{-1}$.

The $\beta$ phase content of each membrane was calculated from the FTIR spectra by applying 24 :

$$
F(\beta)=\frac{A_{\beta}}{\left(K_{\beta} / K_{\alpha}\right) A_{\alpha}+A_{\beta}}
$$

Where, $F(\beta)$ represents the $\beta$ phase content; $A_{\alpha}$ and $A_{\beta}$ the absorbencies at 766 and 840 $\mathrm{cm}^{-1}$, corresponding to the $\alpha$ and $\beta$ phase material; $K_{\alpha}$ and $K_{\beta}$ are the absorption coefficient at the respective wave number. The value of $K_{\alpha}$ is $6.1 \times 10^{4}$ and $K_{\beta}$ is $7.7 \times 10^{4} \mathrm{~cm}^{2} / \mathrm{mol}^{24}$. Differential scanning calorimetry (DSC) measurements were performed at a heating rate of $10^{\circ} \mathrm{C} \cdot \mathrm{min}^{-1}$ in a Mettler-Toledo DSC822e apparatus with Sample Robot TS 0801 RO. The samples were cut into small pieces from membrane middle region and placed into 40 $\mu \mathrm{L}$ aluminum pans. All experiments were carried out under nitrogen atmosphere and at temperature between 25 and $200{ }^{\circ} \mathrm{C}$.

The degree of crystallinity $\left(\chi_{c}\right)$ was calculated from the enthalpy of the melting peak $\left(\Delta \mathrm{H}_{\mathrm{f}}\right)$ based on the enthalpy of a $100 \%$ crystalline sample, through the following equation: 


$$
\chi_{C}=\frac{\Delta H_{f}}{x \Delta H_{\alpha}+y \Delta H_{\beta}}
$$

where $x$ is the weight fraction of the $\alpha$ phase, $y$ is the weight fraction of the $\beta$ phase determined from the FTIR measurements and calculated by equation $1, \Delta H_{\alpha}$ is the melting enthalpy of pure crystalline $\alpha$ PVDF and $\Delta H_{\beta}$ is the melting enthalpy of pure crystalline $\beta$ PVDF which are reported to be $93.04 \mathrm{~J} / \mathrm{g}$ and $103.4 \mathrm{~J} / \mathrm{g}$, respectively ${ }^{38,39}$. Thermogravimetry analyses was performed on a thermal analyzer TGA/SDTA 851e Mettler Toledo. The samples were heated from 25 to $900{ }^{\circ} \mathrm{C}$, at a heating rate of $10{ }^{\circ} \mathrm{C}$ $\min ^{-1}$, under a nitrogen flow rate of $50 \mathrm{~mL} \mathrm{~min}^{-1}$.

\subsection{DEGREE OF POROSITY AND UPTAKE VALUE}

The degree of porosity of the samples $(\varepsilon)$ was determinate by the pycnometer method:

$$
\varepsilon=\frac{W_{2}-W_{3}-W_{s}}{W_{1}-W_{3}}
$$

where $\mathrm{W}_{\mathrm{s}}$ and $\mathrm{W}_{1}$ are the weight of the sample and the weight of the pycnometer filled with ethanol, respectively. The weight of the system after the sample is placed within the pycnometer and ethanol added to complete the volume of the pycnometer is defined as $\mathrm{W}_{2}$. Further, $\mathrm{W}_{3}$ is the residual weight of the pycnometer with ethanol once the sample is removed. The value of the degree of porosity of the samples was calculated for each membrane as the average of the measurements performed in three samples.

The uptake was calculated after equation through the immersion the membranes in the electrolyte solution (1M LiPF 6 in EC:DEC) for 16 hours:

$$
\text { uptake }=\frac{W_{1}-W_{0}}{W_{0}} \times 100
$$


Where $\mathrm{W}_{0}$ and $\mathrm{W}_{1}$ are the weight of the separator before and after absorbing the electrolyte.

\subsection{ELECTROCHEMICAL CHARACTERIZATION}

Impedance spectroscopy measurements of the separator membranes were carried out at room temperature with a Biologic VMP3 instrument at frequencies between $1 \mathrm{MHz}$ to 10 $\mathrm{mHz}$ with an amplitude of $10 \mathrm{mV}$. The ionic conductivity $\left(\sigma_{\text {eff }}\right)$ of the separator membranes was determined by the following equation:

$$
\sigma_{e f f}=\frac{d}{R_{b} \times A}
$$

where $\mathrm{R}_{\mathrm{b}}$ is the bulk resistance, $\mathrm{d}$ is the thickness and $\mathrm{A}$ is the area of the separator membrane.

Another relevant parameters for battery separators, tortuosity $(\tau)$ and MacMullin number $\left(N_{\mathrm{M}}\right)$, were determined by equations 6 and 7 , respectively:

$$
\begin{gathered}
\sigma_{\text {eff }}=\sigma_{0} \frac{\varepsilon}{\tau^{2}} \\
N_{M}=\frac{\sigma_{0}}{\sigma_{e f f}}
\end{gathered}
$$

where $\sigma_{0}$ is the conductivity of the pure liquid electrolyte, $\sigma_{\text {eff }}$ is the room temperature conductivity of the membrane plus the liquid electrolyte and $\varepsilon$ is the degree of porosity of the membrane. 


\subsection{ELECTRODE AND HALF-CELL PREPARATION AND TESTING}

The cathode electrode was prepared from a slurry prepared with $\mathrm{C}-\mathrm{LiFePO}_{4}$ as active material, carbon black as conductive additive and PVDF polymer binder in a weight of 80: 10: $10 \mathrm{wt} \%$ in NMP solvent. The active material mass loading was $2.5 \mathrm{mg} . \mathrm{cm}^{-2}$. The slurry was casted on an aluminum foil through doctor-blade technique and dried at 100 ${ }^{\circ} \mathrm{C}$ for $4 \mathrm{~h}$ in a conventional oven, Binder (ED23 oven). More details about the electrode preparation are reported in ${ }^{40}$.

The $\mathrm{Li} / \mathrm{C}-\mathrm{LiFePO}_{4}$ half-cells (2016 coin-type) were assembled and sealed inside an argon-filled glove box $\left(\mathrm{O}_{2}\right.$ and $\left.\mathrm{H}_{2} \mathrm{O}<0.1 \mathrm{ppm}\right)$. They were composed by lithium metallic disc (10 mm diameter) as anode, a swollen membrane prepared from PVDF and its copolymers (14 mm diameter) and $\mathrm{C}-\mathrm{LiFePO}_{4}$ electrode as cathode (10 $\mathrm{mm}$ diameter). Cycling performance was evaluated at room temperature in the voltage range of $2.5 \mathrm{~V}$ to 4.2 $\mathrm{V}$ at current rates from $\mathrm{C} / 10$ to $2 \mathrm{C}\left(\mathrm{C}=170 \mathrm{mAh} \cdot \mathrm{g}^{-1}\right)$ using a multichannel Maccor 4200 potentiostat. 


\section{RESULTS}

\subsection{PHYSICO-CHEMICAL PROPERTIES OF THE MEMBRANES}

The microstructures (the surface view as well as cross-section) of the as-prepared PVDF and co-polymer membranes are presented in Figure 1. All membranes reveled spongelike porous microstructure with micrometer size interconnected pores. The pores are homogeneously distributed along the thickness of the membrane. This structure is explained through the binary phase diagram of the polymer/DMF system, in which a phase separation between the polymer and the solvent occurs during the solvent evaporation process, i.e, precipitation situation dominated by liquid-liquid demixing ${ }^{30}$. Further, at low temperatures $\left(\sim 25^{\circ} \mathrm{C}\right)$, the polymer chains have lower mobility and does not occupy the free space left by the solvent ${ }^{20,21,30}$. It is already demonstrated that the membrane morphology based on interconnected pores facilitate the migration of lithium ions during the charge-discharge cycling ${ }^{41}$. 



Figure 1. Cross-section and surface (insert) SEM images for PVDF (a), PVDF-TrFE (b), PVDF-HFP (c) and PVDF-CTFE (d) membranes.

On the other hand, the size and shape of the micro pores are different for the different membranes, as can be observed in the surface images of Figure 1. In case of PVDF, PVDF-HFP and PVDF-CTFE membranes, the average pore diameter is $\phi \sim 1 \mu \mathrm{m}$, whereas in case of PVDF-TrFE it is ranging from 2.5 to $4 \mu \mathrm{m}$. This effect is mainly related to the different viscosity of the polymer solutions, in particular for PVDF-TrFE which shows a larger molecular weight distribution and lower molecular weight in comparison with PVDF and PVDF-HFP ${ }^{42}$.

Considering this morphology, the evaluation of the degree of porosity is an important parameter affecting the electrochemical properties of the battery separator ${ }^{43}$. 
Figure 2a) shows the degree of porosity for the different membranes, calculated using equation 3. It is observed that the degree of porosity is $56 \%$ for PVDF-HFP and $72 \%$, for PVDF-TrFE. Thus, the degree of porosity is higher than the one of commercial separators (Celgard 2400, $\varepsilon=41 \%$ ) and in the agreement of the theoretical optimal value, which should be above $50 \%$. It is relevant to mention that the higher degree of porosity leads to higher absorption of electrolyte solution ${ }^{44}$.

The uptake value of the electrolyte solution is shown in table 1 and it ranges between 66 $\%$ (for PVDF) and $84 \%$ (for PVDF-CTFE) ${ }^{43}$. The uptake value is proportional to the degree of porosity of the membranes, hence larger for the co-polymers.

The infrared spectra of the different membranes are shown in Figure 2b. All membranes reveal the specific vibration bands characteristics of the $\alpha$ phase $\left(765,796\right.$ and $\left.976 \mathrm{~cm}^{-1}\right)$ and $\beta$ phase $\left(840 \mathrm{~cm}^{-1}\right)$ of PVDF $^{24}$. The size of these vibration bands is different for each membrane and the $\beta$ phase content, calculated from equation 1 and is presented in table 1.

PVDF shows a $\beta$ phase content of $60 \%$, which is attributed to the preferential all-trans conformation of the polymer chains for solvent evaporation temperatures below $80{ }^{\circ} \mathrm{C}^{29}$. In relation to the co-polymers membranes, PVDF-TrFE shows the highest $\beta$ phase content $(\sim 100 \%)$ due to the inclusion of the monomer of $\operatorname{TrFE}{ }^{24}$. For other co-polymers, the $\beta$ phase content is also determined both on the inclusion of HFP or CTFE monomers as well as on the solvent evaporation temperature ${ }^{30,45}$. The $\beta$ phase content in the membrane is in following order: PVDF-TrFE > PVDF-HFP > PVDF > PVDF-CTFE. 

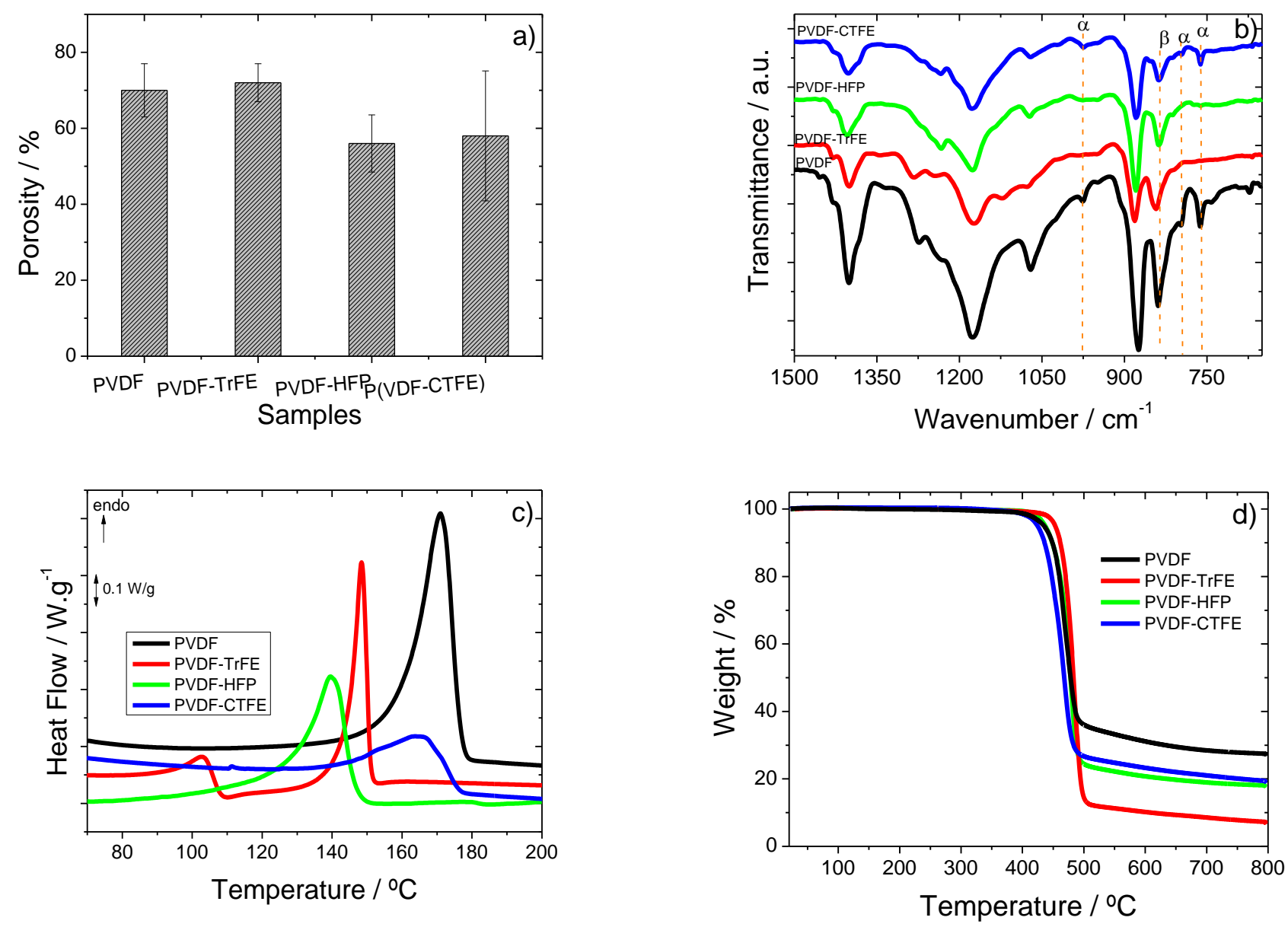

Figure 2. Degree of porosity (a), FTIR-ATR spectra (b), DSC scans (c) and TGA curves

(d) for the different membranes.

The thermal properties of the membranes were determined through DSC scans (Figure 2c) and TGA thermogram (Figure 2d). The degree of crystallinity was obtained from the DSC scans using equation 2 (table 1).

The DSC heating scans of the membranes (Figure 2c) show for all samples the endothermic peak corresponding to the melting of the crystalline phase. The melting temperature for the different membranes ranges between $\sim 140{ }^{\circ} \mathrm{C}$ and $170{ }^{\circ} \mathrm{C}$, in which the minimum value is observed for PVDF-HFP and the maximum value is obtained PVDF. Thus, the co-polymerization process destabilizes the crystalline phase of PVDF 46. For PVDF-TrFE membrane, a second endothermic peak is observed below the melting 
peak that corresponds to the ferroelectric (FE) phase - paraelectric (PE) phase transition (Curie transition) at $\sim 103{ }^{\circ} \mathrm{C}{ }^{43}$. The degree of crystallinity was obtained from the DSC scans through the application of equation 2 (table 1).

Table 1. $\beta$ phase content, degree of crystallinity and uptake value for the all separator membranes.

\begin{tabular}{|c|c|c|c|}
\hline Samples & $\boldsymbol{\beta}$-phase / \% $\mathbf{2} \%$ & $\chi / \% \pm \mathbf{4} \%$ & Uptake / \% $\mathbf{\%} \%$ \\
\hline PVDF & 60 & 55 & 66 \\
\hline PVDF-TrFE & 100 & 28 & 84 \\
\hline PVDF-HFP & 75 & 33 & 79 \\
\hline PVDF-CTFE & 32 & 22 & 80 \\
\hline
\end{tabular}

The degree of crystallinity for PVDF is $\sim 55 \%$, being significantly lower for the different co-polymers.

Whereas for the co-polymers membranes, the degree of crystallinity is between $22 \%$ and $33 \%$. The high amorphous content is beneficial for achieving a higher ionic conductivity 47.

Figure 2d) shows the TGA curves of the membranes, all showing a similar single degradation stage between $390{ }^{\circ} \mathrm{C}$ and $500{ }^{\circ} \mathrm{C}$ and is related to chain-stripping where carbon-hydrogen $(\mathrm{C}-\mathrm{H})$ bond scission occurs, leading to the formation of hydrogen fluoride $(\mathrm{HF})^{48}$. 


\subsection{IONIC CONDUCTIVITY AND BATTERY PERFORMANCE}

The ionic conductivity of the membranes was determined by impedance spectroscopy at room temperature after the uptake process. Representative Nyquist plots are shown in Figure 3.

Independently of the membrane, Figure 3 shows an inclined straight line in all frequency range, indicative of the electrode/electrolyte double layer capacitance behavior ${ }^{49}$.

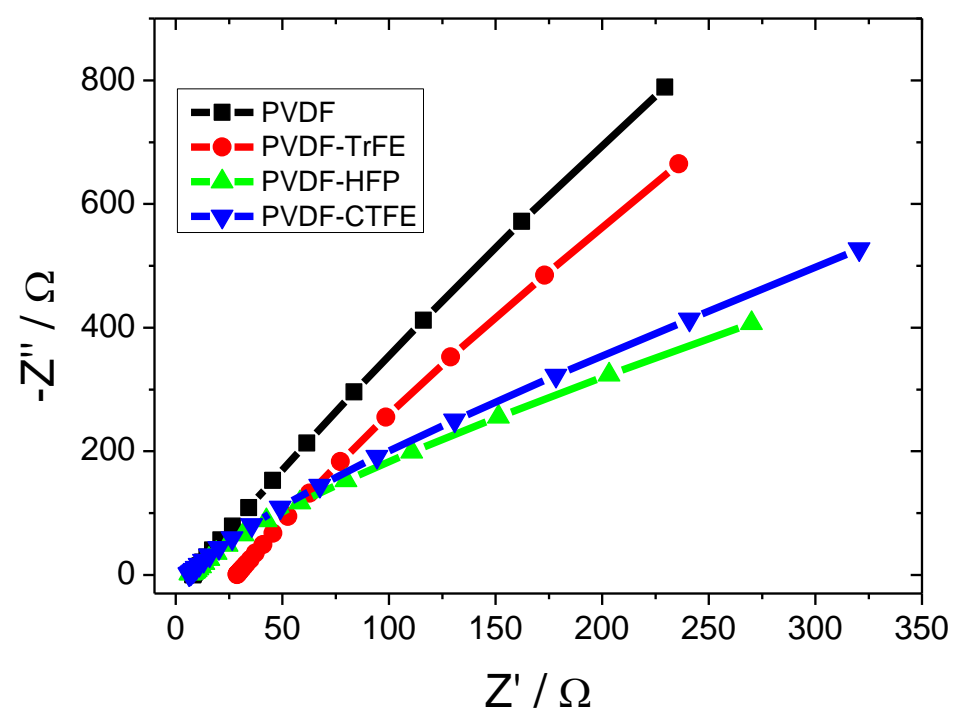

Figure 3. Nyquist plot at room temperature for the different separator membranes.

The ionic conductivity was calculated by equation 5 where the resistance value is determined from the high-frequency side of the Nyquist plot from the intersection of the straight line with the real axis ${ }^{19}$ (table 2). 
Table 2. Room temperature ionic conductivity $(\sigma i)$, tortuosity $(\tau)$ and MacMullin number $\left(\mathrm{N}_{\mathrm{m}}\right)$ for the separator membranes.

\begin{tabular}{|c|c|c|c|}
\hline Samples & $\boldsymbol{\sigma}_{\mathbf{i}} / \mathbf{~ m S . c m}^{\mathbf{1}}$ & $\boldsymbol{\tau}$ & $\mathbf{N}_{\mathbf{m}}$ \\
\hline PVDF & 1.5 & 2.0 & 5.5 \\
\hline PVDF-TrFE & 1.1 & 2.3 & 7.5 \\
\hline PVDF-HFP & 1.3 & 1.9 & 6.3 \\
\hline PVDF-CTFE & 1.5 & 1.8 & 5.5 \\
\hline
\end{tabular}

Table 2 shows that the ionic conductivity value is similar for all membranes (i.e, 1.1 to $1.5 \mathrm{mS} . \mathrm{cm}^{-1}$ ), independently of the morphological characteristics of the membranes. Further, this value is higher than the minimum required value $\left(10^{-4}{\mathrm{~S} . \mathrm{cm}^{-1}}^{-1}\right.$ for lithium battery applications.

Tortuosity and the MacMullin number $\left(\mathrm{N}_{\mathrm{m}}\right)$ were calculated by equation 6 and 7 , respectively, and these values are also similar for the different membranes. In particular, the tortuosity is between 1.8 to 2.3 , very close to the ideal value $\tau=1$, which describes the pore connectivity leading to faster ion transport ${ }^{18}$.

The MacMullin number $\left(\mathrm{N}_{\mathrm{m}}\right)$ describes the resistivity of the electrolyte within the porous membrane and the obtained value ranges between 5.5 and 7.5 for the different membranes, which indicate a relatively low resistivity. This small value is determined by the tortuosity, degree of porosity and electrolyte uptake value of the membranes.

In order to evaluate separator performance, $\mathrm{Li} / \mathrm{C}-\mathrm{LiFePO}_{4}$ coin cells were assembled and the cyclability of the separators was tested at room temperature between $2.5 \mathrm{~V}$ to $4.0 \mathrm{~V}$ and different scan rates $(\mathrm{C} / 10$ to $2 \mathrm{C})$, the results are presented figure 4 .

Figure 4a shows that the first charge-discharge profile of the PVDF sample at different C rates $(\mathrm{C} / 10$ to $2 \mathrm{C})$ is characterized by two voltage pseudoplateaus at $3.1 \mathrm{~V}$ and $3.8 \mathrm{~V}$, 
representing the typical electrochemical behavior of the $\mathrm{C}-\mathrm{LiFePO}_{4}$ spinel, i.e, reversible charge (lithium removal) - discharge (lithium insertion) cycling process ${ }^{50}$.

This plateau corresponds to the $\mathrm{Fe}^{2+} / \mathrm{Fe}^{3+}$ redox reaction and is dependent on the C-rate as it is shown in Figure 4a. The capacity value decreases with increasing C-rate due to the ohmic polarization effect related to the electrolyte diffusion kinetics ${ }^{49}$. The similar behavior is also observed for the co-polymer membranes (data not shown).

Figure $4 \mathrm{~b}$ represents the first charge-discharge curves at $2 \mathrm{C}$ rates for all membranes. At $2 \mathrm{C}$, the voltage profile is stable, and the discharge capacity are $118 \mathrm{mAh} . \mathrm{g}^{-1}, 107 \mathrm{mAh} . \mathrm{g}^{-}$ 1, $102 \mathrm{mAh} \cdot \mathrm{g}^{-1}$ and $85 \mathrm{mAh} . \mathrm{g}^{-1}$ for PVDF-TrFE, PVDF-HFP, PVDF and PVDF-CTFE, respectively.
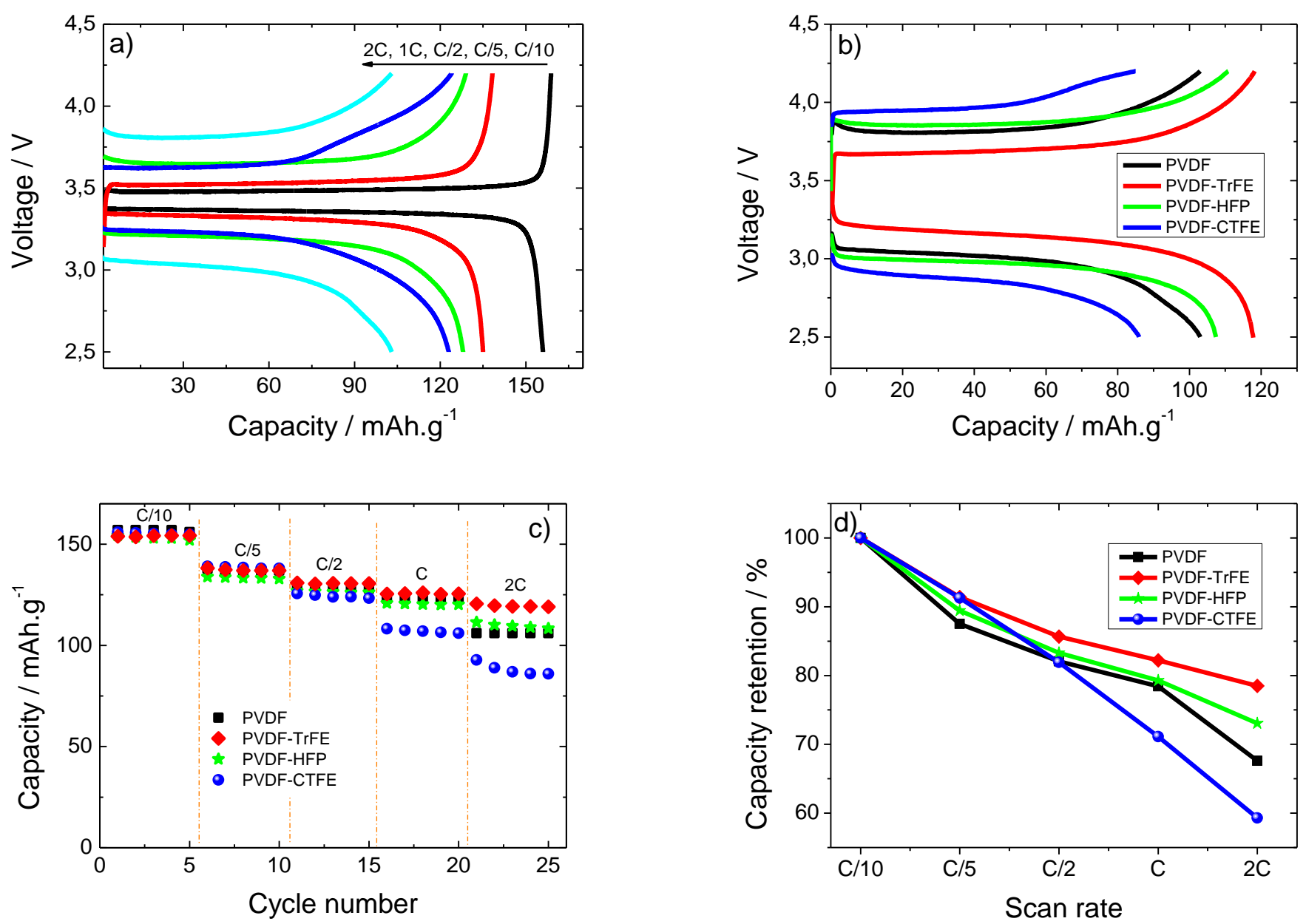
Figure 4. Charge-discharge profiles for the PVDF membrane (a). For the different separator membranes: $2 \mathrm{C}$ rate (b), rate performance as a function of cycle number (c) and capacity retention (d) during the discharge process.

Figure $4 \mathrm{c}$ shows the comparison of the rate performance of the different membranes. Independently of the C-rate, the cycling performance is very stable as a function of the cycling number and decreases more rapidly for PVDF-CTFE membrane. For C-rates below $\mathrm{C}$, the capacity value is very similar for all membranes except for the $\mathrm{C} / 5$-rate where the capacity retention of the PVDF-CTFE membrane is similar to the one for the PVDF-TrFE membrane. For high C-rate (2C-rate), the capacity value decreases in the following order: PVDF-TrFE > PVDF-HFP > PVDF > PVDF-CTFE. It is to notice that this behavior is according to the $\beta$ phase content in the membranes (table 1), being an indication of the relevance of this parameter for battery performance. This fact also is demonstrated through the capacity retention (capacity normalized with respect to the nominal one) as a function of the C-rate (Figure $4 d$ ).

All membranes show a progressive decrease of the capacity value with increasing C-rate, which is associated to the diffusion phenomena taking place within the electrode active material phase and polymer electrolyte separator membrane ${ }^{51}$. The membrane that present the best capacity retention is PVDF-TrFE that shows $78 \%$ in charge and/or discharge process in half an hour (2C). Considering that the membrane with the best cycling performance is PVDF-TrFE and comparing the results at room temperature with PVDF membranes ${ }^{52}\left(136 \mathrm{mAh} \mathrm{g}^{-1}\right.$ for $\mathrm{C}$ rate) and green polymer membranes (Lignin ${ }^{53}$ : $137 \mathrm{mAh} . \mathrm{g}^{-1}$ for C-rate; Cellulose ${ }^{26}: 130 \mathrm{mAh} . \mathrm{g}^{-1}$ for $\mathrm{C} / 2$-rate, etc.) reported in the literature for the same electrode, it is observed that the battery performance reported in the present work is in certain cases better than the one for the PVDF membranes and green polymers. It is to notice, nevertheless, that a direct comparison is not possible as 
the degree of porosity, electrolyte absorption and ionic conductivity are not similar for the different membranes presented in the literature.

The cycling performance of the membranes at $2 \mathrm{C}$ during 50 cycles is shown in figure 5 . After 50 cycles, the capacity values are $87 \mathrm{mAh} \cdot \mathrm{g}^{-1}, 77 \mathrm{mAh} \cdot \mathrm{g}^{-1}, 72 \mathrm{mAh} \cdot \mathrm{g}^{-1}$ and 68 mAh.g ${ }^{-1}$ for PVDF-TrFE, PVDF-HFP, PVDF and PVDF-CTFE, respectively, also following the $\beta$ phase content of the samples.



Figure 5. Cycling performance of the membranes when cycled at 2C.

Figure 5 also shows that the coulombic efficiency (CE) is about $100 \%$ for all samples, related to the reversibility of the process. 


\section{DISCUSSION}

The parameters affecting the cycling performance of the separators are the ionic conductivity value, degree of porosity, uptake, degree of crystallinity and $\beta$-phase content of the membranes.

The ionic conductivity value of the different membranes is practically the same but the degree of porosity varies in $20 \%$, the uptake in $15 \%$ and the degree of crystallinity in $30 \%$ for the different membranes. It is to notice that those variations are small in terms of separator characteristics, to account for the observed performance variations. The polar $\beta$ phase content of the polymer separator membrane, on the other hand, is another relevant parameter that can be affect the battery performance. This parameter has not been considered in the literature as much as other structural or morphological elements, and for this reason, the different separators prepared in the present work present variations of $\beta$ phase contents up to $60 \%$.

Figure 6 shows the capacity retention at $2 \mathrm{C}$ for all membranes as a function of the $\beta$ phase content.

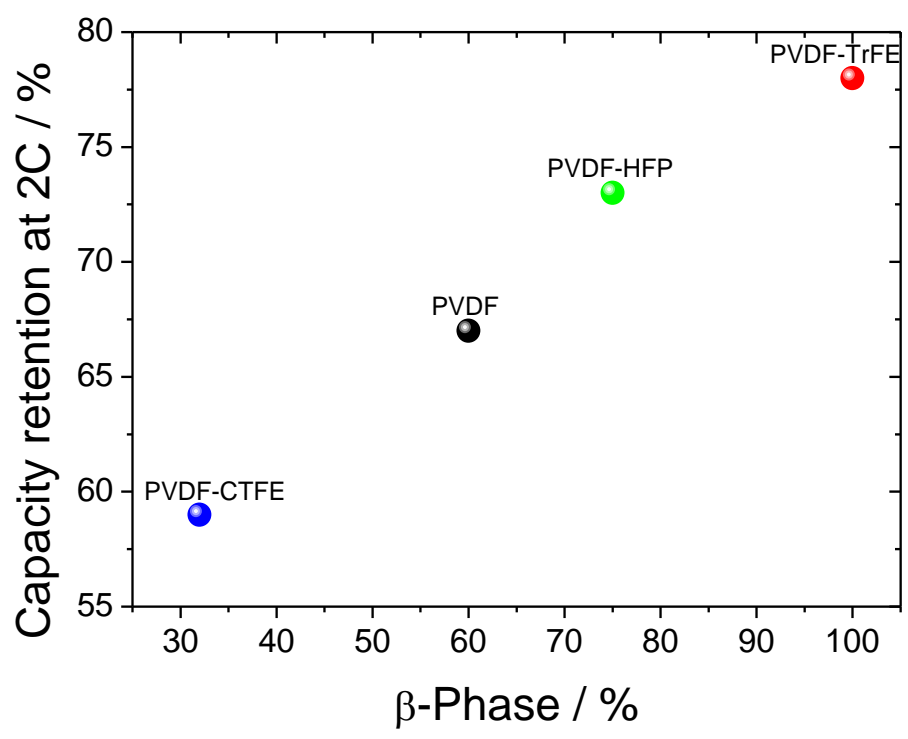

Figure 6. Capacity retention as a function of $\beta$ phase content for the different membranes 
Thus, it is demonstrated that the capacity retention increases with increasing $\beta$ phase content (figure 6).

PVDF and its copolymers are semicrystalline polymer composed by small crystallites with typical dimensions of $\sim 10 \mathrm{~nm}$ organized in groups of lamellas, with partially oriented amorphous intra-lamella phase as represented in the figure 7 . The uptake value is correlated to the degree of porosity and the electrolyte solution penetrating within the pores of the membrane. The pore space would be reduced by the swelling of the amorphous region of the polymer as illustrated in the figure 7 a) ${ }^{54}$. As a result, the ionic conductivity of the membrane, indicative of ion transport and migration, will be also determined on large-scale segmental motions of the polymer chains in the amorphous region ${ }^{55}$. The observed variation of these parameters among the different membranes, as well as the observed variation of the degree of crystallinity, is not large enough to play a significant role into the cycling performance of the battery ${ }^{9,10}$ (Figures 4 and 5). The polar $\beta$ phase is characterized by the parallel alignment of chain dipoles in the unit cell, which gives rise to the spontaneous crystal polarization as it is shown in figure $7 b^{56}$. The local electric field that stabilizes the parallel alignment of chain dipoles in the $\beta$ phase will act for movement of the lithium ions.

The $\beta$ phase is the most polar of the phases of PVDF, due to the all-trans conformation of the monomers within the polymer chain, showing also the largest dielectric constant: $\varepsilon \sim 7$ for the $\alpha$ phase and $\varepsilon \sim 12$ for the $\beta$ phase of PVDF ${ }^{39,57} . \alpha-P V D F$, on the other hand, shows a trans-gauche conformation and a non-polar unit cell ${ }^{24}$. Thus, larger $\beta$ phase contents facilitates fast lithium ions migration on the separator and enhances the binding affinity of lithium ions at high-scan rate, promoting to reach the active materials to store lithium ions ${ }^{58}$. 
PVDF and its copolymers contain polar functional -C-F group (as it is shown in Figure 7 for $\beta$ phase) where the fluorine ions can dissociate into the electrolyte solution, induce a negatively charged diffuse layer and a positively charged capillary wall ${ }^{59}$.

Figure 7 shows the schematic representation of the interaction between the positive charged lithium ions and the fluorine atoms into $\beta$ phase with higher dipole moment (black arrow).

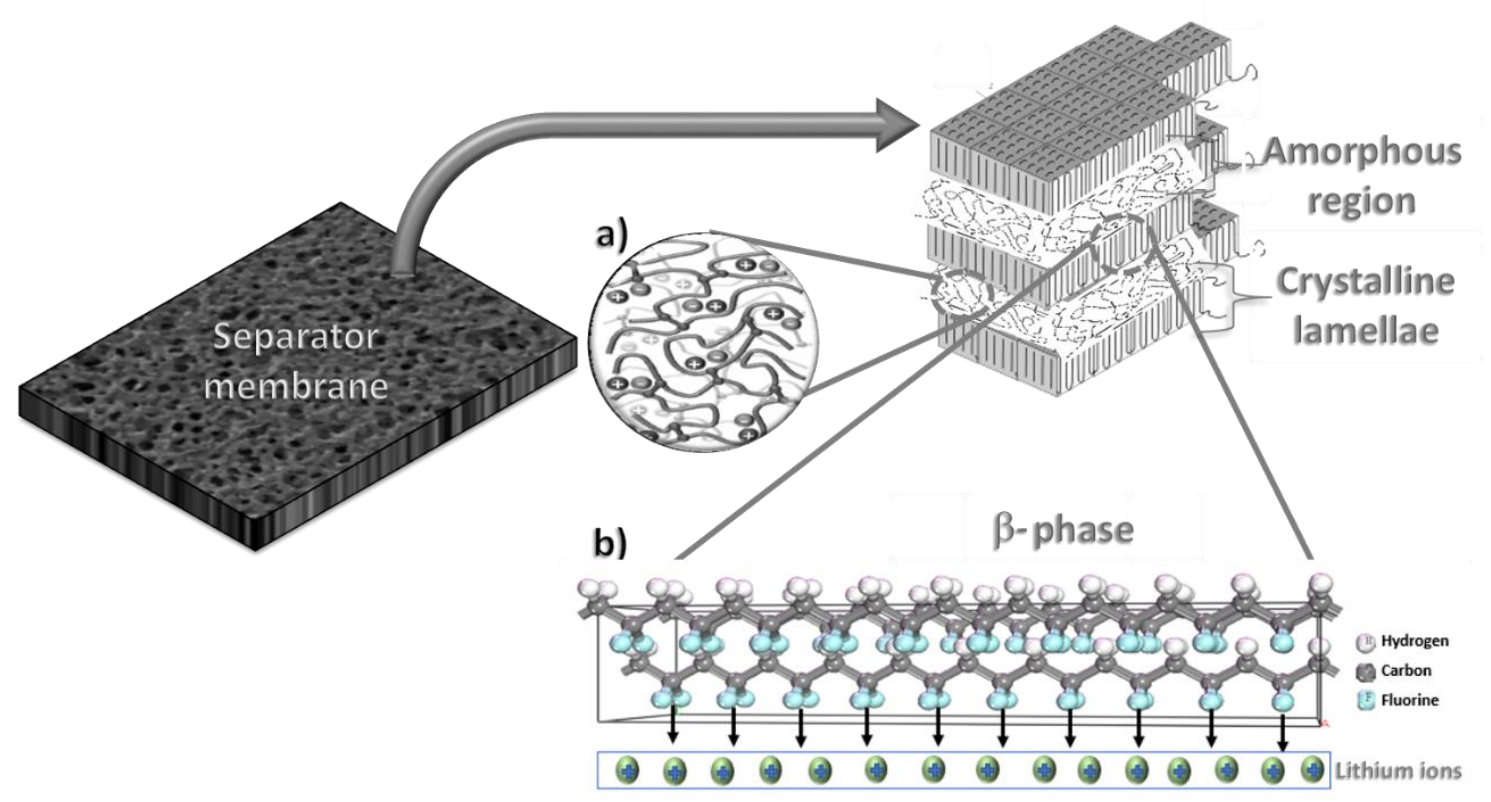

Figure 7. Schematic representation of the interaction between lithium ions and the fluorine atoms of the $\beta$ phase of PVDF.

Theoretical simulations of PVDF as a binder demonstrate that the interaction energy between PVDF and LFP surface is stronger when the polarization axis is parallel to the substrate, facilitating lithium ion transport in charge-discharge processes ${ }^{58}$. The binding affinity of Li-ion was estimated by calculating its adsorption energy $\left(\Delta \mathrm{E}_{\text {ads }}\right)$ where $\Delta \mathrm{E}_{\text {ads }}$ $=-3.04 \mathrm{eV}$ for $\beta$ phase and $\Delta \mathrm{E}_{\mathrm{ads}}=-0.72 \mathrm{eV}$ for $\alpha$ phase) demonstrating the higher binding affinity for the $\beta$ phase of the polymer ${ }^{58}$. This fact also is verified in this case for the battery separator. 


\section{CONCLUSIONS}

The relevance of the polar $\beta$ phase content in the performance of PVDF base separator membranes into Li-ion batteries has been demonstrated. Separator membranes based on poly(vinylidene fluoride), PVDF, and their co-polymers poly(vinylidene fluoride-cotrifluoroethylene), PVDF-TrFE, poly(vinylidene fluoride-co-hexafluropropylene), PVDF-HFP and poly(vinylidene fluoride-co-chlorotrifluoroethylene), PVDF-CTFE were prepared by a solvent casting method at the same polymer/solvent ratio and solvent evaporation temperature. All membranes show a similar porous microstructure with variations of $16 \%$ in the degree of porosity and of $20 \%$ in the degree of crystallinity. On the other hand, variation up to $70 \%$ were achieved in the polar $\beta$ phase of the different membranes. The ionic conductivity, electrolyte uptake, tortuosity and MacMullin number

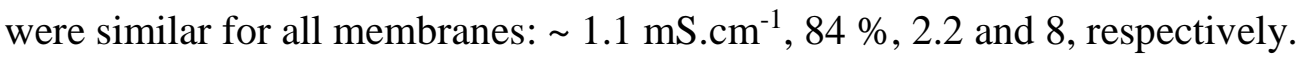

All membranes showed good cyclability and rate capability. At the C-rate of $2 \mathrm{C}$, the capacity values after 50 cycles are $87 \mathrm{mAh} . \mathrm{g}^{-1}, 77 \mathrm{mAh} . \mathrm{g}^{-1}, 72 \mathrm{mAh} \cdot \mathrm{g}^{-1}$ and $68 \mathrm{mAh} . \mathrm{g}^{-1}$ for PVDF-TrFE, PVDF-HFP, PVDF and PVDF-CTFE, respectively, showing a close correlation with the $\beta$-phase content of the membranes, which facilitates the fast lithium ions migration through the separator.

Thus, based on this work, it can be concluded that the $\beta$ phase content of the polymer membranes has to be maximized in order to improve the power density of lithium-ion batteries. 


\title{
AUTHOR INFORMATION
}

\section{Corresponding Author}

\section{cmscosta@fisica.uminho.pt; senentxu.lanceros@bcmaterials.net}

\author{
Author Contributions
}

The manuscript was written through contributions of all authors. All authors have given approval to the final version of the manuscript

\section{Notes}

The authors declare no competing financial interest.

\section{ACKNOWLEDGMENTS}

This work was supported by the Portuguese Foundation for Science and Technology (FCT) in the framework of the Strategic Funding UID/FIS/04650/2013. The authors thank FEDER funds through the COMPETE 2020 Programme and National Funds through FCT under the projects PTDC/CTM-ENE/5387/2014 and UID/CTM/50025/2013 and grants SFRH/BD/90215/2012 (J.C.D.) and SFRH/BPD/112547/2015 (C.M.C.). The authors acknowledge funding by the Spanish Ministry of Economy and Competitiveness (MINECO) through the project MAT2016-76039-C4-3-R (AEI/FEDER, UE) (including the FEDER financial support) and from the Basque Government Industry Department under the ELKARTEK Program. Authors are grateful to the Government of the Basque Country for financial support (Grupos de Investigación, IT718-13). The authors thank Solvay, Timcal and Phostech for kindly supplying the high quality materials. 


\section{REFERENCES}

(1) Luo, X.; Wang, J.; Dooner, M.; Clarke, J., Overview of current development in electrical energy storage technologies and the application potential in power system operation. Applied Energy 2015, 137, 511-536.

(2) Kularatna, N., Energy Storage Devices for Electronic Systems: Rechargeable Batteries and Supercapacitors. ed.; Elsevier Science: 2014.

(3) Whittingham, M. S., History, Evolution, and Future Status of Energy Storage. Proceedings of the IEEE 2012, 100, (Special Centennial Issue), 1518-1534.

(4) Krajačić, G.; Duić, N.; Zmijarević, Z.; Mathiesen, B. V.; Vučinić, A. A.; da Graça Carvalho, M., Planning for a 100\% independent energy system based on smart energy storage for integration of renewables and $\mathrm{CO} 2$ emissions reduction. Applied Thermal Engineering 2011, 31, (13), 2073-2083.

(5) Jacobson, M. Z.; Delucchi, M. A., A path to sustainable energy by 2030. Scientific American 2009, 301, (5), 58-65.

(6) Chen, H.; Cong, T. N.; Yang, W.; Tan, C.; Li, Y.; Ding, Y., Progress in electrical energy storage system: A critical review. Progress in Natural Science 2009, 19, (3), 291312.

(7) Goodenough, J. B.; Park, K.-S., The Li-Ion Rechargeable Battery: A Perspective. Journal of the American Chemical Society 2013, 135, (4), 1167-1176.

(8) Nitta, N.; Wu, F.; Lee, J. T.; Yushin, G., Li-ion battery materials: present and future. Materials Today 2015, 18, (5), 252-264. 
(9) Costa, C. M.; Silva, M. M.; Lanceros-Mendez, S., Battery separators based on vinylidene fluoride (VDF) polymers and copolymers for lithium ion battery applications. RSC Advances 2013, 3, (29), 11404-11417.

(10) Nunes-Pereira, J.; Costa, C. M.; Lanceros-Méndez, S., Polymer composites and blends for battery separators: State of the art, challenges and future trends. Journal of Power Sources 2015, 281, 378-398.

(11) $\mathrm{Xu}, \mathrm{K}$., Nonaqueous Liquid Electrolytes for Lithium-Based Rechargeable Batteries. Chemical Reviews 2004, 104, (10), 4303-4418.

(12) Huang, X., Separator technologies for lithium-ion batteries. Journal of Solid State Electrochemistry 2011, 15, (4), 649-662.

(13) Chung, Y. S.; Yoo, S. H.; Kim, C. K., Enhancement of Meltdown Temperature of the Polyethylene Lithium-Ion Battery Separator via Surface Coating with Polymers Having High Thermal Resistance. Industrial \& Engineering Chemistry Research 2009, 48, (9), 4346-4351.

(14) Venugopal, G.; Moore, J.; Howard, J.; Pendalwar, S., Characterization of microporous separators for lithium-ion batteries. Journal of Power Sources 1999, 77, (1), $34-41$.

(15) Kang, Y.; Kim, H. J.; Kim, E.; Oh, B.; Cho, J. H., Photocured PEO-based solid polymer electrolyte and its application to lithium-polymer batteries. Journal of Power Sources 2001, 92, (1-2), 255-259.

(16) Huang, B.; Wang, Z.; Li, G.; Huang, H.; Xue, R.; Chen, L.; Wang, F., Lithium ion conduction in polymer electrolytes based on PAN. Solid State Ionics 1996, 85, (1-4), 7984. 
(17) Costa, C. M.; Nunes-Pereira, J.; Sencadas, V.; Silva, M. M.; Lanceros-Méndez, S., Effect of fiber orientation in gelled poly(vinylidene fluoride) electrospun membranes for Li-ion battery applications. Journal of Materials Science 2013, 48, (19), 6833-6840.

(18) Djian, D.; Alloin, F.; Martinet, S.; Lignier, H., Macroporous poly(vinylidene fluoride) membrane as a separator for lithium-ion batteries with high charge rate capacity. Journal of Power Sources 2009, 187, (2), 575-580.

(19) Costa, C. M.; Gomez Ribelles, J. L.; Lanceros-Méndez, S.; Appetecchi, G. B.; Scrosati, B., Poly(vinylidene fluoride)-based, co-polymer separator electrolyte membranes for lithium-ion battery systems. Journal of Power Sources 2014, 245, 779786.

(20) Sousa, R. E.; Nunes-Pereira, J.; Costa, C. M.; Silva, M. M.; Lanceros-Méndez, S.; Hassoun, J.; Scrosati, B.; Appetecchi, G. B., Influence of the porosity degree of poly(vinylidene fluoride-co-hexafluoropropylene) separators in the performance of Liion batteries. Journal of Power Sources 2014, 263, 29-36.

(21) Sousa, R. E.; Kundu, M.; Goren, A.; Silva, M. M.; Liu, L.; Costa, C. M.; LancerosMendez, S., Poly(vinylidene fluoride-co-chlorotrifluoroethylene) (PVDF-CTFE) lithium-ion battery separator membranes prepared by phase inversion. RSC Advances 2015, 5, (110), 90428-90436.

(22) Zhang, H. P.; Zhang, P.; Li, Z. H.; Sun, M.; Wu, Y. P.; Wu, H. Q., A novel sandwiched membrane as polymer electrolyte for lithium ion battery. Electrochemistry Communications 2007, 9, (7), 1700-1703.

(23) Li, Z. H.; Zhang, P.; Zhang, H. P.; Wu, Y.P.; Zhou, X. D., A lotus root-like porous nanocomposite polymer electrolyte. Electrochemistry Communications 2008, 10, (5), 791-794. 
(24) Martins, P.; Lopes, A. C.; Lanceros-Mendez, S., Electroactive phases of poly(vinylidene fluoride): Determination, processing and applications. Progress in Polymer Science 2014, 39, (4), 683-706.

(25) Zhu, Y.; Wang, F.; Liu, L.; Xiao, S.; Yang, Y.; Wu, Y., Cheap glass fiber mats as a matrix of gel polymer electrolytes for lithium ion batteries. 2013, 3, 3187 .

(26) Xiao, S.; Wang, F.; Yang, Y.; Chang, Z.; Wu, Y., An environmentally friendly and economic membrane based on cellulose as a gel polymer electrolyte for lithium ion batteries. RSC Advances 2014, 4, (1), 76-81.

(27) Bachman, J. C.; Muy, S.; Grimaud, A.; Chang, H.-H.; Pour, N.; Lux, S. F.; Paschos, O.; Maglia, F.; Lupart, S.; Lamp, P.; Giordano, L.; Shao-Horn, Y., Inorganic Solid-State Electrolytes for Lithium Batteries: Mechanisms and Properties Governing Ion Conduction. Chemical Reviews 2016, 116, (1), 140-162.

(28) Nakajima, T.; Groult, H., Fluorinated Materials for Energy Conversion. ed.; Elsevier Science: 2005.

(29) Ferreira, J. C. C.; Monteiro, T. S.; Lopes, A. C.; Costa, C. M.; Silva, M. M.; Machado, A. V.; Lanceros-Mendez, S., Variation of the physicochemical and morphological characteristics of solvent casted poly(vinylidene fluoride) along its binary phase diagram with dimethylformamide. Journal of Non-Crystalline Solids 2015, 412, $16-23$.

(30) Sousa, R. E.; Ferreira, J. C. C.; Costa, C. M.; Machado, A. V.; Silva, M. M.; Lanceros-Mendez, S., Tailoring poly(vinylidene fluoride-co-chlorotrifluoroethylene) microstructure and physicochemical properties by exploring its binary phase diagram with dimethylformamide. Journal of Polymer Science Part B: Polymer Physics 2015, 53, (11), 761-773. 
(31) Cardoso, V. F.; Botelho, G.; Lanceros-Méndez, S., Nonsolvent induced phase separation preparation of poly(vinylidene fluoride-co-chlorotrifluoroethylene) membranes with tailored morphology, piezoelectric phase content and mechanical properties. Materials \& Design 2015, 88, 390-397.

(32) Ferreira, C. G.; Cardoso, V. F.; Lopes, A. C.; Botelho, G.; Lanceros-Méndez, S., Tailoring microstructure and physical properties of poly(vinylidene fluoridehexafluoropropylene) porous films. Journal of Materials Science 2015, 50, (14), 50475058.

(33) Lang, W.-Z.; Guo, Y.-J.; Chu, L.-F., Evolution of the precipitation kinetics, morphologies, permeation performances, and crystallization behaviors of polyvinylidenefluoride (PVDF) hollow fiber membrane by adding different molecular weight polyvinylpyrrolidone (PVP). Polymers for Advanced Technologies 2011, 22, (12), $1720-1730$.

(34) Ribeiro, C.; Sencadas, V.; Ribelles, J. L. G.; Lanceros-Méndez, S., Influence of Processing Conditions on Polymorphism and Nanofiber Morphology of Electroactive Poly(vinylidene fluoride) Electrospun Membranes. Soft Materials 2010, 8, (3), 274-287. (35) Hietala, S.; Holmberg, S.; Karjalainen, M.; Nasman, J.; Paronen, M.; Serimaa, R.; Sundholm, F.; Vahvaselka, S., Structural investigation of radiation grafted and sulfonated poly(vinylidene fluoride), PVDF, membranes. Journal of Materials Chemistry 1997, 7, (5), 721-726.

(36) Kim, J. F.; Jung, J. T.; Wang, H. H.; Lee, S. Y.; Moore, T.; Sanguineti, A.; Drioli, E.; Lee, Y. M., Microporous PVDF membranes via thermally induced phase separation (TIPS) and stretching methods. Journal of Membrane Science 2016, 509, 94-104.

(37) Costa, C. M.; Rodrigues, L. C.; Sencadas, V.; Silva, M. M.; Rocha, J. G.; Lanceros-Méndez, S., Effect of degree of porosity on the properties of poly(vinylidene 
fluoride-trifluorethylene) for Li-ion battery separators. Journal of Membrane Science 2012, 407-408, 193-201.

(38) Lanceros-Méndez, S.; Mano, J. F.; Costa, A. M.; Schmidt, V. H., FTIR AND DSC STUDIES OF MECHANICALLY DEFORMED $\beta$-PVDF FILMS. Journal of Macromolecular Science, Part B 2001, 40, (3-4), 517-527.

(39) Lovinger, A. J., Poly(Vinylidene Fluoride). In Developments in Crystalline Polymers-1, Bassett, D. C., Ed. Springer Netherlands: Dordrecht, 1982; pp 195-273.

(40) Gören, A.; Cíntora-Juárez, D.; Martins, P.; Ferdov, S.; Silva, M. M.; Tirado, J. L.; Costa, C. M.; Lanceros-Méndez, S., Influence of Solvent Evaporation Rate in the Preparation of Carbon-Coated Lithium Iron Phosphate Cathode Films on Battery Performance. Energy Technology 2016, 4, (5), 573-582.

(41) Zhang, H.; Ma, X.; Lin, C.; Zhu, B., Gel polymer electrolyte-based on PVDF/fluorinated amphiphilic copolymer blends for high performance lithium-ion batteries. RSC Advances 2014, 4, (64), 33713-33719.

(42) Bottino, A.; Capannelli, G.; Munari, S.; Turturro, A., Solubility parameters of poly(vinylidene fluoride). Journal of Polymer Science Part B: Polymer Physics 1988, 26, (4), 785-794.

(43) Gören, A.; Costa, C. M.; Tamaño Machiavello, M. N.; Cíntora-Juárez, D.; NunesPereira, J.; Tirado, J. L.; Silva, M. M.; Gomez Ribelles, J. L.; Lanceros-Méndez, S., Effect of the degree of porosity on the performance of poly(vinylidene fluoridetrifluoroethylene)/poly(ethylene oxide) blend membranes for lithium-ion battery separators. Solid State Ionics 2015, 280, 1-9.

(44) Miranda, D.; Costa, C. M.; Almeida, A. M.; Lanceros-Méndez, S., Modeling separator membranes physical characteristics for optimized lithium ion battery performance. Solid State Ionics 2015, 278, 78-84. 
(45) Sousa, R. E.; Nunes-Pereira, J.; Ferreira, J. C. C.; Costa, C. M.; Machado, A. V.;

Silva, M. M.; Lanceros-Mendez, S., Microstructural variations of poly(vinylidene fluoride co-hexafluoropropylene) and their influence on the thermal, dielectric and piezoelectric properties. Polymer Testing 2014, 40, 245-255.

(46) Ma, W.; Yuan, H.; Wang, X., The Effect of Chain Structures on the Crystallization Behavior and Membrane Formation of Poly(Vinylidene Fluoride) Copolymers. Membranes 2014, 4, (2), 243-256.

(47) Raghavan, P.; Zhao, X.; Manuel, J.; Chauhan, G. S.; Ahn, J.-H.; Ryu, H.-S.; Ahn, H.-J.; Kim, K.-W.; Nah, C., Electrochemical performance of electrospun poly(vinylidene fluoride-co-hexafluoropropylene)-based nanocomposite polymer electrolytes incorporating ceramic fillers and room temperature ionic liquid. Electrochimica Acta 2010, 55, (4), 1347-1354.

(48) Costa, C. M.; Machiavello, M. N. T.; Ribelles, J. L. G.; Lanceros-Méndez, S., Composition-dependent physical properties of poly[(vinylidene fluoride)-cotrifluoroethylene]-poly(ethylene oxide) blends. Journal of Materials Science 2013, 48, (9), 3494-3504.

(49) Xiao, W.; Zhao, L.; Gong, Y.; Wang, S.; Liu, J.; Yan, C., Preparation of high performance lithium-ion batteries with a separator-cathode assembly. RSC Advances 2015, 5, (43), 34184-34190.

(50) Nien, Y.-H.; Carey, J. R.; Chen, J.-S., Physical and electrochemical properties of LiFePO4/C composite cathode prepared from various polymer-containing precursors. Journal of Power Sources 2009, 193, (2), 822-827.

(51) Hassoun, J.; Panero, S.; Reale, P.; Scrosati, B., A New, Safe, High-Rate and HighEnergy Polymer Lithium-Ion Battery. Advanced Materials 2009, 21, (47), 4807-4810. 
(52) Costa, C. M.; Rodrigues, H. M.; Gören, A.; Machado, A. V.; Silva, M. M.; Lanceros-Méndez, S., Preparation of Poly(vinylidene fluoride) Lithium-Ion Battery Separators and Their Compatibilization with Ionic Liquid - A Green Solvent Approach. ChemistrySelect 2017, 2, (19), 5394-5402.

(53) Gong, S.-D.; Huang, Y.; Cao, H.-J.; Lin, Y.-H.; Li, Y.; Tang, S.-H.; Wang, M.-S.; Li, X., A green and environment-friendly gel polymer electrolyte with higher performances based on the natural matrix of lignin. Journal of Power Sources 2016, 307, (Supplement C), 624-633.

(54) Idris, N. H.; Rahman, M. M.; Wang, J.-Z.; Liu, H.-K., Microporous gel polymer electrolytes for lithium rechargeable battery application. Journal of Power Sources $\mathbf{2 0 1 2}$, 201, 294-300.

(55) Prasanth, R.; Shubha, N.; Hng, H. H.; Srinivasan, M., Effect of poly(ethylene oxide) on ionic conductivity and electrochemical properties of poly(vinylidenefluoride) based polymer gel electrolytes prepared by electrospinning for lithium ion batteries. Journal of Power Sources 2014, 245, 283-291.

(56) Carbeck, J. D.; Lacks, D. J.; Rutledge, G. C., A model of crystal polarization in $\beta$ poly(vinylidene fluoride). The Journal of Chemical Physics 1995, 103, (23), 1034710355.

(57) Mendes, S. F.; Costa, C. M.; i Serra, R. S.; Baldalo, A. A.; Sencadas, V.; GomezRibelles, J. L.; Gregorio, R.; Lanceros-Méndez, S., Influence of filler size and concentration on the low and high temperature dielectric response of poly(vinylidene fluoride) / $\mathrm{Pb}(\mathrm{Zr} 0.53 \mathrm{Ti0}$.47)O3 composites. Journal of Polymer Research 2012, 19, (9), 9967.

(58) Song, W.-J.; Joo, S. H.; Kim, D. H.; Hwang, C.; Jung, G. Y.; Bae, S.; Son, Y.; Cho, J.; Song, H.-K.; Kwak, S. K.; Park, S.; Kang, S. J., Significance of ferroelectric 
polarization in poly (vinylidene difluoride) binder for high-rate Li-ion diffusion. Nano Energy 2017, 32, 255-262.

(59) Romanyuk, K.; Costa, C. M.; Luchkin, S. Y.; Kholkin, A. L.; Lanceros-Méndez, S., Giant Electric-Field-Induced Strain in PVDF-Based Battery Separator Membranes Probed by Electrochemical Strain Microscopy. Langmuir 2016, 32, (21), 5267-5276. 
TOC Graphic

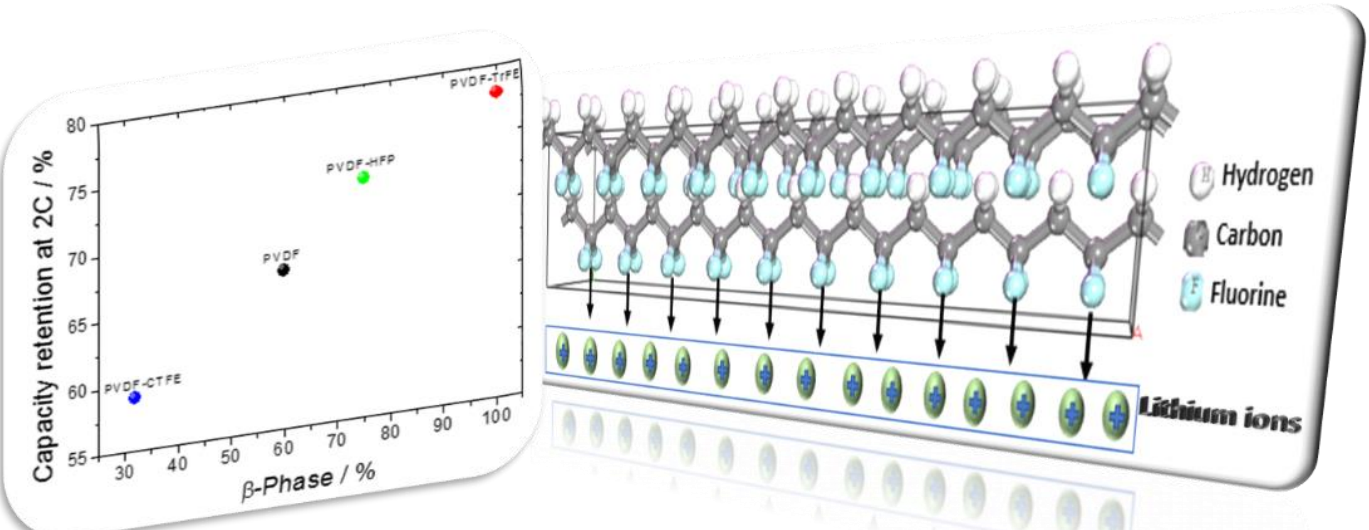

